\title{
MICROPROPAGACIÓN DE VARIEDADES DE CAÑA DE AZÚCAR CULTIVADAS EN MÉXICO
}

\author{
MICROPROPAGATION OF SUGARCANE VARIETIES GROWN IN MÉXICO
}

\author{
S. Eloísa Rangel-Estrada ${ }^{1 *}$, Eleodoro Hernández-Meneses ${ }^{2}$ \\ y Marianguadalupe Hernández-Arenas ${ }^{1}$
}

\begin{abstract}
${ }^{1}$ Campo Experimental Zacatepec, Instituto Nacional de Investigaciones Forestales, Agrícolas y Pecuarias (INIFAP). Km. 0.5 Carr. Zacatepec-Galeana 62780, Zacatepec, Morelos. Tel. 01 (800) 0882222 Ext. 86608. ${ }^{2}$ Postgrado en Recursos Genéticos y Productividad - Fisiología Vegetal, Campus Montecillo, Colegio de Postgraduados. Km 36.5 Carretera México-Texcoco. 56230, Montecillo, Texcoco, Estado de México.
\end{abstract}

*Autor de correspondencia (rangel.sandra@inifap.gob.mx)

\section{RESUMEN}

El cultivo de la caña de azúcar (Saccharum officinarum L.) es uno de los más importantes en México; las 828,609 ha cultivadas en el año 2014 representaron $3.7 \%$ de la superficie nacional cultivable. Las enfermedades causadas por hongos, bacterias, virus y fitoplasmas son uno de los desafíos que enfrenta el cultivo. El objetivo del presente estudio fue desarrollar un sistema de micropropagación de tres variedades de caña de azúcar para obtener plantas sanas para estudios de sanidad. Se desarrolló un sistema de micropropagación clonal de las variedades ITV 92-1424, Laica 82-2220 y Q28-2. La regeneración de plantas se logró vía organogénesis directa a partir de meristemos apicales disecados de plantas madre de seis meses de edad. Los brotes se indujeron en medio de cultivo MS adicionado con concentraciones de 2.5 a $7.5 \mu \mathrm{M}$ de BA. La multiplicación de brotes se obtuvo con las mismas concentraciones de BA en combinación con $1 \mu \mathrm{M}$ de AIA. El enraizamiento in vitro de las tres variedades fue eficiente en medio de cultivo MS con las sales a la mitad de la concentración. La aclimatación se obtuvo a las seis semanas con 95 a $98 \%$ de supervivencia en una mezcla de turba y perlita $(1: 1 \mathrm{v} / \mathrm{v})$

Palabras clave: Saccharum officinarum, cultivo in vitro, meristemos, patogenicidad.

\section{SUMMARY}

Sugarcane (Saccharum officinarum L.) is one of the most important field crops grown in México. In 2014, 828,609 ha were sown and accounted for $3.7 \%$ of the total national cultivated area. However, diseases caused by fungi, bacteria, viruses and phytoplasms are one of the main challenges for cultivation. This research developed a micropropagation system of three varieties to produce entire, healthy plants for pathogenicity studies. A system of clonal propagation of ITV 92-1424, Laica 82-2220 and Q28-2 varieties was developed. Plant regeneration was achieved via organogenesis from apical meristems dissected from six-months old mother plants. Shoots were induced to multiplication in MS medium supplemented with concentrations of 2.5 to 7.5 uM BA. Shoot multiplication was achieved with the same concentrations of $B A$ in combination with $1 \mu \mathrm{M}$ IAA. In vitro rooting of the three varieties was efficient in the MS medium with half-salt concentration. Acclimation of plants was achieved at six weeks with 95 to $98 \%$ survival in a mixture of peat and perlite $(1: 1 \mathrm{v} / \mathrm{v})$.

Index words: Saccharum officinarum, in vitro culture, meristems, pathogenicity.

\section{INTRODUCCIÓN}

La industria azucarera en México es una de las más importantes para la economía; su relevancia social y económica la convierten en una fuente importante de empleos directos e indirectos (Hernández-Cázares, 2014). El cultivo de la caña de azúcar (Saccharum officinarum L.) ocupa el quinto lugar en importancia; la superficie sembrada de 828,609 ha en el año 2014, representó $3.7 \%$ de la superficie total nacional destinada a los cultivos. Los $26,225 \mathrm{mi}-$ llones de pesos del valor de la producción la situaron como el segundo cultivo más importante, sólo por debajo del maíz (Zea mays L.). Se cultiva en 14 estados de la República, entre los cuales Veracruz sobresale como el principal productor con más de 287,000 ha (SIAP, 2015).

Desde hace algunos años esta actividad agrícola se enfrenta a múltiples factores que le impiden expresar su máximo potencial. Algunos de ellos se relacionan con la falta de innovaciones tecnológicas como el uso de riego, fertilización, mecanización y uso de variedades mejoradas adaptadas a las regiones productoras, entre otros. También son importantes las afectaciones ocasionadas por factores de estrés abiótico y biótico (Gómez-Merino et al., 2014). En este último aspecto destacan las enfermedades existentes y emergentes causadas por hongos, bacterias y virus que constituyen una seria amenaza para la producción nacional.

De acuerdo con el Manual Azucarero Mexicano (CNIAA, 2015) en la zafra 2014, la variedad ITV 92-1424 ocupó el cuarto lugar con $6 \%$ de la superficie sembrada con caña de azúcar a nivel nacional, y el primer lugar con $67 \%$ en el estado de Morelos. La variedad Laica 82-2220 se encuentra en etapa de promoción en la zona de abasto del Ingenio Emiliano Zapata en Morelos mientras que la Q28-2 está en fase de selección por su alto potencial de producción 
y se encuentra en proceso de incremento de material vegetativo para su evaluación en fase semi-comercial en el Campo Experimental Zacatepec del Instituto Nacional de Investigaciones Forestales, Agrícolas y Pecuarias (INIFAP).

Las diversas técnicas del cultivo de tejidos vegetales in vitro se fundamentan en la totipotencia celular y consisten en cultivar un explante aséptico en un medio artificial de composición química definida e incubado en condiciones ambientales controladas (Kumar y Singh, 2009). El objetivo final es regenerar una planta completa a partir de un explante, ya sea vía organogénesis o embriogénesis somática (Neumann et al., 2009). Las técnicas de cultivo in vitro son herramientas valiosas para el desarrollo de investigaciones básicas y aplicadas como el mejoramiento genético, la conservación de germoplasma, transformación genética y producción de plantas haploides, entre otras (Srivastava et al., 2013).

La micropropagación es la aplicación más destacada en el cultivo de tejidos; a partir del cultivo de meristemos es posible obtener plantas genéticamente idénticas a la planta madre y propagar a gran escala especies élite, amenazadas, en peligro de extinción, nuevas variedades o las que tienen baja tasa de reproducción de manera natural (George y Debergh, 2008). Para lograr avances que impacten en el sistema de producción de caña de azúcar, es necesario implementar estrategias de innovación, tales como el cultivo in vitro (Castañeda-Castro et al., 2014), que sea eficiente para la obtención de lotes de plantas libres de enfermedades disponibles para determinar relaciones de etiología y estudios de sanidad (Bhojwani y Dantu, 2013; López-Estrada et al., 2008).

Con base en estos antecedentes, la presente investigación tuvo como objetivo desarrollar un sistema de propagación clonal in vitro de tres variedades comerciales de caña de azúcar cultivadas en México para usarlas en evaluaciones futuras de sanidad.

\section{MATERIALES Y MÉTODOS}

\section{Material vegetal y tipo de explante}

Se utilizaron plantas de caña de azúcar cultivadas en campo de las variedades ITV 92-1424, Laica 82-2220 y Q28-2 de seis meses de edad. Se usaron como explantes ápices del tallo principal con una longitud de 0.8 a $1.2 \mathrm{~cm}$ que contenía el meristemo de brote.

\section{Medio de cultivo y condiciones de incubación}

El medio de cultivo básico empleado fue el MS (Murashi- ge y Skoog, 1962) con las sales inorgánicas completas, suplementado con sacarosa $\left(30 \mathrm{~g} \mathrm{~L}^{-1}\right)$, mio-inositol $(100 \mathrm{mg}$ $\left.\mathrm{L}^{-1}\right)$, tiamina $\left(1 \mathrm{mg} \mathrm{L}^{-1}\right)$, carbón activado $\left(0.5 \mathrm{~g} \mathrm{~L}^{-1}\right)$ y agaragar (Merck®, $\left.9.0 \mathrm{~g} \mathrm{~L}^{-1}\right)$. El pH de 5.7 se ajustó con $\mathrm{NaOH}$ o $\mathrm{HCl} 1 \mathrm{~N}$ mediante un potenciómetro (Hanna Instruments ${ }^{\circledR}$ Modelo HI3220, U.S.A.) y la esterilización se hizo en autoclave (Felisa® Modelo FE405, México) a $121^{\circ} \mathrm{C}$ y $1.5 \mathrm{~kg}$ $\mathrm{cm}^{-2}$ de presión por $20 \mathrm{~min}$. Los cultivos se mantuvieron a $25 \pm 2{ }^{\circ} \mathrm{C}$ en fotoperiodo de $16 \mathrm{~h}$ e intensidad luminosa de $45 \mu \mathrm{mol} \mathrm{m}{ }^{-2} \mathrm{~s}^{-1}$ con lámparas de luz blanca.

\section{Establecimiento del cultivo aséptico}

Los meristemos apicales se lavaron con detergente comercial (Romaß) por 5 min; se enjuagaron con agua de la llave y con agua destilada esterilizada. Se sumergieron durante 1 min en etanol (70\%) y después se enjuagaron con agua destilada esterilizada (Figura 1a). En seguida se evaluaron cuatro tratamientos de desinfección que consistieron en dos concentraciones de hipoclorito de sodio $(\mathrm{NaOCl}$, Cloralex®, 20 y $30 \%$ v/v) y dos tiempos de inmersión ( 15 y $20 \mathrm{~min}$ ); a cada tratamiento se le adicionó $0.1 \mathrm{~mL}$ de surfactante (Tween $\left.{ }^{\circledR} 20\right)$. Los explantes se establecieron en frascos de vidrio de $45 \mathrm{~mL}$ de capacidad con $15 \mathrm{~mL}$ de medio de cultivo. A las tres semanas se contabilizó la tasa de supervivencia (\%), ennegrecimiento del explante (\%) y contaminación (\%) por hongos o bacterias.

\section{Inducción y multiplicación de brotes}

Para la inducción de brotes los meristemos apicales se sembraron en el medio básico MS suplementado con cinco concentraciones de benciladenina (BA) (Sigma $\left.{ }^{\circledR}\right)$ : 0 , $2.5,5.0,7.5$ y $10 \mu \mathrm{M}$. Se usaron frascos de vidrio de $45 \mathrm{~mL}$ de capacidad con $15 \mathrm{~mL}$ de medio de cultivo. A las ocho semanas se cuantificó la brotación (determinada como el porcentaje de explantes que generaron brotes), número de brotes por explante y longitud del brote $(\mathrm{cm})$. Los subcultivos a medio fresco se hicieron a las cuatro semanas. Para la multiplicación se seleccionó la mejor concentración hormonal de inducción de brotes y se adicionó ácido indolacético (AIA) $1 \mu \mathrm{M}$. A las cuatro y ocho semanas se cuantificó la brotación y número de brotes por explante.

\section{Alargamiento y enraizamiento de plantas}

Grupos de tres brotes de 4 a $5 \mathrm{~cm}$ de longitud de las tres variedades se cultivaron en medio básico MS sin hormonas, adicionado con las sales minerales en dos concentraciones: completas y a la mitad. Se usaron frascos de vidrio de $500 \mathrm{~mL}$ de capacidad con $80 \mathrm{~mL}$ de medio de cultivo. Después de cuatro semanas se cuantificó el enraizamiento (\%) y la altura de la planta (cm). 


\section{Aclimatación}

Plantas in vitro de 8 a $12 \mathrm{~cm}$ de altura se extrajeron de los frascos; las raíces se lavaron para retirar residuos del medio de cultivo y se sumergieron en solución fungicida (Captagro ${ }^{\circledR}$, $1 \mathrm{~g} \mathrm{~L}^{-1}$ ) por $20 \mathrm{~min}$. En condiciones de invernadero, las plantas se colocaron en macetas de poliestireno de $175 \mathrm{~mL}$ de capacidad en una mezcla de sustrato de turba y perlita (1:1 $\mathrm{V} / \mathrm{v}$ ) esterilizada, y se protegieron con cubierta transparente. Se aplicaron riegos semanales con la fórmula 17N-17P$17 \mathrm{~K}$. De cada variedad se plantaron 50 repeticiones y a las cuatro semanas se retiró la cubierta plástica, y dos semanas después se cuantificó la tasa de supervivencia (\%).

\section{Análisis estadístico}

Todos los experimentos se establecieron en un diseño completamente al azar con 10 repeticiones por tratamiento. La unidad experimental fue un explante por frasco de vidrio o planta por maceta. Los datos obtenidos se sometieron a análisis de varianza con el paquete de análisis estadístico SAS Versión 9.0 (SAS Institute, 2003) y para la comparación de medias se usó la prueba de Tukey $(P \leq$ 0.05).

\section{RESULTADOS Y DISCUSIÓN}

\section{Establecimiento del cultivo aséptico}

La supervivencia, ennegrecimiento y contaminación de los explantes en las tres variedades de caña de azúcar fue afectada por los tratamientos de desinfección $(P \leq 0.05)$ Los porcentajes más altos de supervivencia se obtuvieron con $\mathrm{NaOCl}$ a $20 \%$ (v/v) durante 20 min. La dosis de $30 \%$ $\mathrm{v} / \mathrm{v}$ de $\mathrm{NaOCl}$ fue efectiva para controlar la contaminación; sin embargo, causó ennegrecimiento de los explantes, probablemente debido al efecto tóxico de $\mathrm{NaOCl}$ en los tejidos. La contaminación observada fue producida por bacterias. La dosis de $20 \%$ de $\mathrm{NaOCl}$ favoreció la supervivencia de los explantes sin producir efectos tóxicos, pero $15 \mathrm{~min}$ de inmersión no eliminaron los microorganismos y, en consecuencia, hubo contaminación (30 \%) (Cuadro 1).

Si bien existen reportes de métodos de desinfección para determinadas variedades o genotipos de caña de azúcar (Behera y Sahoo, 2009; Ramanand y Lal, 2004; Tyagi et al., 2010), éstos no se pueden generalizar para todas las variedades, y por ello es necesario desarrollar un tratamiento óptimo para cada una porque los microorganismos, no necesariamente patógenos, pueden afectar en diferente magnitud los tejidos y causar contaminación in vitro. En este caso, en las tres variedades establecidas se tuvieron buenos resultados de supervivencia y asepsia al aplicar 20 $\%$ de cloro comercial por $20 \mathrm{~min}$.

Aunque existen diversos productos químicos que se pueden emplear para desinfectar tejidos vegetales (e.g. hipoclorito de calcio, cloruro de mercurio, plata coloidal estable, entre otros), el $\mathrm{NaOCl}$ es uno de los más efectivos. Este compuesto tiene una fuerte propiedad oxidante y es altamente reactivo con aminoácidos, ácidos nucleicos, aminas y amidas (Fukuzaki, 2006). La efectividad del

Cuadro 1. Porcentaje de supervivencia, ennegrecimiento y contaminación de meristemos apicales de tres variedades de caña de azúcar sembradas bajo condiciones asépticas.

\begin{tabular}{|c|c|c|c|c|c|}
\hline \multirow{2}{*}{ Variable } & \multirow{2}{*}{$\mathrm{DMSH}^{+}$} & \multicolumn{4}{|c|}{$\mathrm{NaOCl}(\%)+$ tiempo (min) } \\
\hline & & $20+15$ & $20+20$ & $30+15$ & $30+20$ \\
\hline & \multicolumn{5}{|c|}{ ITV 92-1424 } \\
\hline Supervivencia (\%) & 36.3 & $70 a b$ & 90 a & $60 a b$ & $50 \mathrm{~b}$ \\
\hline Ennegrecimiento (\%) & 38.5 & $0 \mathrm{~b}$ & $0 \mathrm{~b}$ & $40 \mathrm{a}$ & $50 \mathrm{a}$ \\
\hline \multirow{2}{*}{ Contaminación (\%) } & 32.4 & 30 a & 10 a & $0 \mathrm{a}$ & $0 \mathrm{a}$ \\
\hline & \multicolumn{5}{|c|}{ Laica 82-2220 } \\
\hline Supervivencia (\%) & 35.7 & $50 \mathrm{~b}$ & $100 \mathrm{a}$ & $50 \mathrm{~b}$ & $40 \mathrm{~b}$ \\
\hline Ennegrecimiento (\%) & 38.5 & $0 \mathrm{~b}$ & $0 \mathrm{~b}$ & $50 \mathrm{a}$ & $60 \mathrm{a}$ \\
\hline \multirow[t]{2}{*}{ Contaminación (\%) } & 32.2 & $50 \mathrm{a}$ & $0 \mathrm{~b}$ & $0 \mathrm{~b}$ & $0 \mathrm{~b}$ \\
\hline & \multicolumn{5}{|c|}{ Q28-2 } \\
\hline Supervivencia (\%) & 36.3 & $60 a b$ & 90 a & $70 a b$ & $50 \mathrm{~b}$ \\
\hline Ennegrecimiento (\%) & 38.7 & $0 \mathrm{~b}$ & $0 \mathrm{~b}$ & $30 a b$ & $50 \mathrm{a}$ \\
\hline Contaminación (\%) & 34.7 & $40 a$ & $10 a b$ & $0 \mathrm{~b}$ & $0 \mathrm{~b}$ \\
\hline
\end{tabular}


$\mathrm{NaOCl}$ se incrementa si se adiciona un agente surfactante que reduzca la tensión superficial y pueda penetrar los tejidos (Smith, 2013). El primer paso en un sistema de propagación in vitro es establecer el cultivo aséptico donde sobreviva e inicie su crecimiento una cantidad aceptable de explantes (George y Debergh, 2008), como se obtuvo en este caso que fue de 90 a $100 \%$ de supervivencia en las tres variedades estudiadas.

\section{Inducción y multiplicación de brotes}

La inducción de los brotes en los explantes fue promovida por la dosis de BA adicionada al medio de cultivo en las tres variedades de caña de azúcar $(P \leq 0.05)$. La brotación fue $100 \%$ en todas las concentraciones probadas, incluso en el tratamiento testigo sin hormona. Esta respuesta indica que las tres variedades mostraron capacidad morfogénica para inducir la organogénesis directa en función del estímulo hormonal; sin embargo, entre las variedades esta capacidad fue diferente y se reflejó en la cantidad de brotes generados por explante y en concentraciones hormonales distintas. En ITV 92-1424 la mayor cantidad de brotes (6.9) se obtuvo con $7.5 \mu \mathrm{M}$ de BA, mientras que Laica 82-2220 produjo 7.8 brotes con $5 \mu \mathrm{M}$ de BA. La variedad Q28-2 formó 25.8 brotes con $2.5 \mu \mathrm{M}$ de BA, que significa más del doble de la cantidad obtenida en la otras dos variedades (Figura $1 \mathrm{~b}-\mathrm{c}$ ). Con respecto al tamaño de los brotes, éstos alcanzaron en promedio $5.6 \mathrm{~cm}$ en las tres variedades (Cuadro 2).

La capacidad morfogénica de los cultivos in vitro está fuertemente determinada por la especie, incluso a nivel de variedades (Neumann et al., 2009). Este aspecto se observó en los resultados obtenidos en las tres variedades de caña de azúcar evaluadas, donde cada una expresó la máxima cantidad de brotes en diferentes dosis de BA. La brotación alcanzada con el medio de cultivo sin hormonas indica que de forma natural las variedades de caña evaluadas tienen la capacidad genética de generar brotes y ésta es una de las características por las que se explotan en plantaciones comerciales (Berding et al., 2004).

Es importante señalar que la organogénesis directa se obtuvo sólo con la adición de benciladenina. En unas variedades la inducción de la organogénesis también ha sido posible sólo con BA, pero en otras se requirió su combinación con otra citocinina. En la variedad CP 77400 la organogénesis directa (1.8 brotes por explante) se indujo con 6.6 $\mu \mathrm{M}$ de BA mientras que en la variedad BL-4 se logró con $2.2 \mu \mathrm{M}$ de $\mathrm{BA}+1.1 \mu \mathrm{M}$ de cinetina (Ali et al., 2008). En las variedades Co 449 y Co 678 la mayor cantidad de brotes (7.8 y 9.1, respectivamente) se obtuvo con $8.8 \mu \mathrm{M}$ de BA combinada con 1.1 $\mathrm{MM}$ de cinetina (Mekonnen et al., 2014). La organogénesis directa en la variedad NCo376 fue viable con las mismas citocininas pero en dosis bajas de $0.45 \mu \mathrm{M}$ de BA y $0.07 \mu \mathrm{M}$ de cinetina (Ramgareeb et al., 2010).

Para la multiplicación de brotes se seleccionó la concentración hormonal que mayor cantidad de brotes produjo en la etapa de inducción en cada variedad y se le adicionó 1 $\mu \mathrm{M}$ de AIA. En estas condiciones se mantuvieron durante dos ciclos de cultivo de cuatro semanas cada uno. La brotación fue $100 \%$ en las tres variedades en ambos ciclos. En la variedad ITV 92-1424 la cantidad de brotes generados fue de 9.4 y 10.3 a las cuatro y ocho semanas, respectivamente, que representaron un incremento promedio de $42 \%$ con respecto a los obtenidos en la etapa de inducción. Para la variedad Laica 82-2220 fueron 11.2 y 12.5 brotes a las cuatro y ocho semanas, respectivamente; lo que representa $51 \%$ de incremento. En la variedad Q28-2 se generaron 27.9 y 29.9 brotes a las cuatro y ocho semanas, respectivamente, y sólo representaron un aumento de 12 \% comparados con los obtenidos en la etapa de inducción (Figura 1 d-e).

La multiplicación de brotes en las tres variedades fue mejorada cuando se adicionó AIA a la mejor dosis de BA obtenida en la etapa de inducción. Esta respuesta se debe fundamentalmente al papel que ejerce el balance entre auxinas y citocininas sobre la morfogénesis in vitro y por ello se emplean comúnmente en la multiplicación de brotes (Gaba, 2005). Específicamente, las auxinas junto con las citocininas están involucradas en la iniciación de yemas y el crecimiento; la división celular parece estar regulada por ambas y cada una influye en las diferentes fases del ciclo celular. El AIA es una de las auxinas que tiene un fuerte efecto sobre el alargamiento celular cuando se usa en concentraciones de 0.1 a $10 \mu \mathrm{M}$ (Machakova et al., 2008).

\section{Alargamiento y enraizamiento de plantas}

La altura de planta, el número de raíces por planta y la longitud de las mismas fueron afectados por la concentración de sales en el medio de cultivo en las tres variedades $(P \leq 0.05)$. De forma consistente, las sales completas del medio de cultivo MS favorecieron el alargamiento de las plantas pero redujeron la formación de raíces y su longitud en las tres variedades. Con el medio de cultivo a la mitad de la concentración de sales minerales el sistema radicular fue mayor y más compacto (Cuadro 3, Figura 1 f).

Durante la etapa de multiplicación, los cultivos de las tres variedades mostraron capacidad organogénica para la formación de raíces. Sin embargo, se probaron tratamientos de enraizamiento para mejorar la respuesta y preparar las plantas para la etapa de aclimatación. El enraizamiento durante la multiplicación de brotes se presenta en algunas especies, y en estos casos, se facilita al retirar 


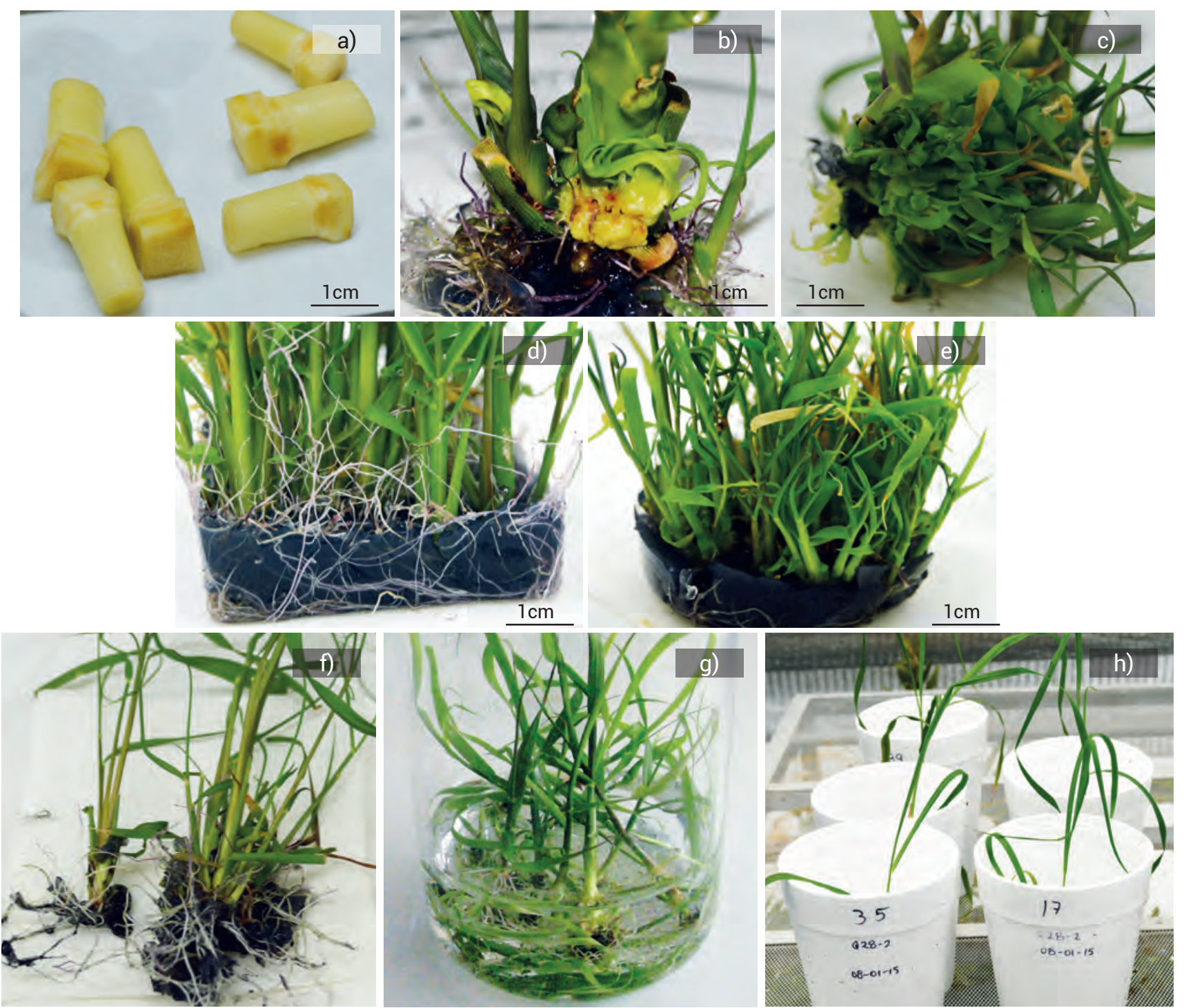

Figura 1. Micropropagación de tres variedades comerciales de caña de azúcar. a) Explantes desinfectados de var. ITV 92-1424; b) Inducción de brotes en var. Laica 82-2220 con $5 \mu \mathrm{M}$ de BA; c) Var. Q28-2 con $2.5 \mu \mathrm{M}$ de BA; d) Multiplicación de brotes en var. Q28-2 con $2.5 \mu \mathrm{M}$ de BA + $1 \mu \mathrm{M}$ de AIA; e) Variedad ITV 92-1424 con $7.5 \mu \mathrm{M}$ de BA + $1 \mu \mathrm{M}$ de AIA; f) Enraizamiento de plantas de var. Laica 82-2220 en medio MS con la mitad de sales; g) Plantas enraizadas de var. Q28-2 para aclimatación; h) Plantas aclimatadas de var. Q28-2 a las seis semanas.

Cuadro 2. Inducción de brotes a partir de meristemos apicales de tres variedades de caña de azúcar a las ocho semanas de cultivo en medio MS.

\begin{tabular}{|c|c|c|c|c|c|c|}
\hline \multirow{2}{*}{$\mathrm{BA}(\mu \mathrm{M})$} & \multicolumn{2}{|c|}{ ITV 92-1424 } & \multicolumn{2}{|c|}{ Laica 82-2220 } & \multicolumn{2}{|c|}{ Q28-2 } \\
\hline & Brotes (Núm.) & Long. brote (cm) & Brotes (Núm.) & Long. brote $(\mathrm{cm})$ & Brotes (Núm.) & Long. brote $(\mathrm{cm})$ \\
\hline 0 & $1.8 \mathrm{~d}$ & $6.3 \mathrm{a}$ & $2.3 \mathrm{~d}$ & $5.4 a b$ & $3.8 \mathrm{~d}$ & $5.8 \mathrm{a}$ \\
\hline 2.5 & $5.3 \mathrm{~b}$ & $5.7 \mathrm{ab}$ & $6.6 \mathrm{~b}$ & $5.7 a b$ & $25.8 \mathrm{a}$ & $5.7 \mathrm{a}$ \\
\hline 5 & $4.6 \mathrm{~b}$ & $6.5 \mathrm{a}$ & 7.8 a & 6.4 a & $17.1 \mathrm{~b}$ & $5.8 \mathrm{a}$ \\
\hline 7.5 & 6.9 a & $5.4 b$ & $4.6 \mathrm{c}$ & $5.1 \mathrm{~b}$ & $14.4 \mathrm{~b}$ & $5.1 \mathrm{a}$ \\
\hline 10 & $3.1 \mathrm{c}$ & $5.7 \mathrm{ab}$ & $3.1 \mathrm{~d}$ & $5.6 \mathrm{ab}$ & $11.1 \mathrm{C}$ & $4.9 \mathrm{a}$ \\
\hline $\mathrm{DMSH}^{+}$ & 1.04 & 0.86 & 0.95 & 1.12 & 3.20 & 1.36 \\
\hline
\end{tabular}

Medias con letras iguales en las columnas no son estadísticamente diferentes (Tukey, 0.05). $\mathrm{DMSH}^{+}=$diferencia mínima significativa honesta. 
Cuadro 3. Alargamiento y enraizamiento in vitro de plántulas de tres variedades de caña de azúcar a las cuatro semanas de cultivo en medio MS.

\begin{tabular}{lcccc}
\hline Variedad & MS $(\%)$ & Altura de planta $(\mathrm{cm})$ & Núm. de raíces & Longitud de raíz $(\mathrm{cm})$ \\
\hline ITV 92-1424 & 100 & $15.2 \mathrm{c}$ & $7.1 \mathrm{~d}$ & $10.8 \mathrm{a}$ \\
& 50 & $11.4 \mathrm{e}$ & $15.7 \mathrm{~b}$ & $7.2 \mathrm{c}$ \\
Laica 82-2220 & 100 & $17.3 \mathrm{~b}$ & $9.2 \mathrm{~cd}$ & $8.9 \mathrm{~b}$ \\
& 50 & $13.3 \mathrm{~d}$ & $20.7 \mathrm{a}$ & $5.5 \mathrm{~d}$ \\
Q28-2 & 100 & $20.1 \mathrm{a}$ & $11.3 \mathrm{c}$ & $9.5 \mathrm{ab}$ \\
& 50 & $13.5 \mathrm{~cd}$ & $19.6 \mathrm{a}$ & $4.8 \mathrm{~d}$ \\
$\mathrm{DMSH}^{+}$ & 1.89 & 2.28 & 1.64 \\
\hline
\end{tabular}

Medias con letras iguales en las columnas no son estadísticamente diferentes (Tukey, 0.05). $\mathrm{DMSH}^{+}=$diferencia mínima significativa honesta.

las hormonas o reducir a la mitad las sales del medio de cultivo (Ramanand et al., 2007).

\section{Aclimatación}

La aclimatación de plantas de caña de azúcar micropropagadas puede considerarse un proceso exitoso si se brindan las condiciones óptimas de sustrato, humedad y temperatura. La tasa de supervivencia de plantas de las tres variedades micropropagadas en este estudio fue $95 \%$ en la variedad ITV 92-1424, $97 \%$ en Laica $82-2220$ y $98 \%$ en la variedad Q28-2. Las condiciones de invernadero proporcionaron el ambiente adecuado de humedad relativa (90 $\%)$ y temperatura $\left(25^{\circ} \mathrm{C}\right)$ para alcanzar estos porcentajes de supervivencia. La mezcla de perlita y turba favoreció el enraizamiento de las tres variedades, las cuales lograron su aclimatación después de seis semanas (Figura $1 \mathrm{~g}$-h).

Este sistema de micropropagación desarrollado para las variedades de caña de azúcar ITV 92-1424, Laica 82-2220 y Q28-2, vía organogénesis directa a partir de meristemos apicales, es un proceso eficiente para obtener lotes clonales de plantas que se puedan emplear para estudios de sanidad de diferentes patógenos. Mediante los ajustes específicos, este sistema se podría emplear para la propagación de una decena de genotipos élite de caña de azúcar que se cultivan en México. El protocolo también podría integrarse para la obtención de plantas de otras variedades de caña si se determinan las condiciones hormonales precisas para cada una. Además, en las tres variedades estudiadas el protocolo podría aplicarse para diversos estudios como variación somaclonal, selección in vitro, mutagénesis y la obtención plantas libres de virus.

\section{CONCLUSIONES}

Se desarrolló un protocolo de micropropagación para las variedades de caña de azúcar ITV 92-1424, Laica 82-2220 y Q28-2. La regeneración de plantas fue vía organogénesis directa a partir de meristemos apicales de plantas madre de seis meses de edad. La inducción de brotes se logró en medio de cultivo MS adicionado con dosis de 2.5 a $7.5 \mu \mathrm{M}$ de BA y la multiplicación de brotes se alcanzó con estas mismas concentraciones combinadas con $1 \mu \mathrm{M}$ de AIA. El enraizamiento de las plantas de las tres variedades fue eficiente en medio MS a la mitad de la concentración de sales. La mayor supervivencia de plantas aclimatadas se obtuvo a las seis semanas en mezcla de turba y perlita $(1: 1 \mathrm{v} / \mathrm{v})$.

\section{AGRADECIMIENTOS}

Al banco de germoplasma de caña de azúcar del Campo Experimental Zacatepec-INIFAP, por el material vegetal proporcionado, y a las Ing. Quím. Lilia González Teodocio y Karina Sánchez Zúñiga por su valioso apoyo en el laboratorio.

\section{BIBLIOGRAFÍA}

Ali A., S. Naz, F. A. Siddiqui and J. Iqbal (2008) An efficient protocol for large scale production of sugarcane through micropropagation. Pakistan Journal of Botany 40:139-149.

Behera K. K. and S. Sahoo (2009) Rapid in vitro micropropagation of sugarcane (Saccharum officinarum L. cv. Nayana) through callus culture. Nature and Science 7:1-10.

Berding N., M. Hogarth and M. Cox (2004) Plant improvement of sugarcane. In: Sugarcane. G. James (ed.). 2nd ed. Blackwell Publishing. Oxford, UK. pp:20-47.

Bhojwani S. S. and P. K. Dantu (2013) Plant Tissue Culture: An Introductory Text. Springer. New Delhi, India. 309 p.

Castañeda-Castro O., F. C. Gómez-Merino, L. I. Trejo-Téllez, V. Morales-Ramos, M. T. González-Arnao, Y. M. Martínez-Ocampo, R. Gámez-Pastrana y M. C. Pastelín-Solano (2014) Aplicaciones del cultivo de tejidos vegetales en caña de azúcar (Saccharum spp). Agroproductividad 7:16-21.

CNIAA, Cámara Nacional de las Industrias Azucarera y Alcoholera (2015) Manual Azucarero Mexicano $58^{\circ}$ ed. México, D.F. 505 p.

Fukuzaki S. (2006) Mechanisms of actions of sodium hypochlorite in cleaning and disinfection processes. Biocontrol Science 11:147-157

Gaba V. P. (2005) Plant growth regulators in plant tissue culture and development. In: Plant Development and Biotechnology. R. N. Trigiano and D. J. Gray (eds.). CRC Press. Boca Raton, FL, U.S.A. pp:87-99.

George E. F. and P. C. Debergh (2008) Micropropagation: uses and methods. 
In: Plant Propagation by Tissue Culture. Vol. 1. The Background E. F. George, M. A. Hall and G. J. De Klerck (eds.). Springer, The Netherlands. pp:29-64.

Gómez-Merino F. C., L. I. Trejo-Téllez, V. Morales-Ramos, J. Salazar-Ortiz, J. Velasco-Velasco, H. E. Sentíes-Herrera y P. Ladewig (2014) Necesidades de innovación en la producción de caña de azúcar (Saccharum spp). Agroproductividad 7:22-26.

Hernández-Cázares A. S. (2014) La agroindustria de la caña de azúcar (Saccharum officinarum) en México. Agroproductividad 7:3541.

Kumar S. and M. P. Singh (2009) Plant Tissue Culture. APH Publishing Corporation. New Delhi, India. $286 \mathrm{p}$.

López-Estrada M. E., M. C. Acosta-Rodríguez, G. Otero-Colina, A. C. MichelAceves y D. H. Noriega-Cantú (2008) Manejo de plántulas de mango (Mangifera indica L.) obtenidas in vitro para estudios de sanidad vegetal. Revista Mexicana de Fitopatología 26:184-187.

Machakova I., E. Zazimalova and E. F. George (2008) Plant growth regulators I: introduction; auxins, their analogues and inhibitors. In: Plant Propagation by Tissue Culture. Vol. 1. The Background E. F. George, M. A. Hall and G. J. De Klerck (eds.). Springer, The Netherlands. pp: 175-204.

Mekonnen T., M. Diro, M. Sharma and T. Negi (2014) Protocol optimization for in vitro mass propagation of two sugarcane (Saccharum officinarum L.) clones grown in Ethiopia. African Journal of Biotechnology 13:1358-1368.

Murashige T. and F. Skoog (1962) A revised medium for rapid growth and bioassays with tobacco tissue cultures. Physiologia Plantarum 15:473-497.
Neumann K. H., A. Kumar and J. Imani (2009) Plant Cell and Tissue Culture-A Tool in Biotechnology. Basics and Application. SpringerVerlag. Berlin-Heidelberg. 333 p.

Ramanand and M. Lal (2004) An efficient protocol for in vitro micropropagation of sugarcane. Sugar Tech 6:85-87.

Ramanand, M. Lal, S. B. Singh and V. P. Singh (2007) Optimization of rooting in micropropagated shoots of sugarcane. Sugar Tech 9:95-97.

Ramgareeb S., S. J. Snyman, T. van Antwerpen and R. S. Rutherford (2010) Elimination of virus and rapid propagation of disease-free sugarcane (Saccharum spp. cultivar NCo376) using apical meristem culture. Plant Cell, Tissue and Organ Culture 100:175-181.

SAS Institute (2003) The SAS system for windows. Release 9.1. SAS Institute. Cary, NC, USA.

SIAP, Servicio de Información Agroalimentaria y Pesquera (2015) Cierre de la producción Agrícola por cultivo. SAGARPA. México. http://www. siap.gob.mx/cierre-de-la-produccion-agricola-por-cultivo/ (Noviembre, 2015).

Smith R. H. (2013) Explant preparation. In: Plant Tissue Culture: Techniques and Experiments. Academic Press. Waltham, MA, USA pp:45-51

Srivastava D. K., G. Gambhir and P. Sharma (2013) Plant cell and tissue culture techniques in crop improvement. In: Biotechnology in Agriculture and Food Processing. Opportunities and Challenges. P. S. Panesar and S. S. Marwaha (eds.). CRC Press. New York, USA. pp:73-131.

Tyagi P., S. Kumar, V. N. Sharma, A. Ojha and V. Ghalout (2010) An efficient protocol for in vitro clonal propagation of two sugarcane varieties (Saccharum officinarum) through callus culture. International Journal of Applied Agricultural Research 5:511-524. 